\title{
Market Separations Perspective of Agricultural Markets and Successful AMIS: Beyond Technical Rationality
}

\author{
Laxmi Gunupudi and Rahul De' \\ Indian Institute of Management Bangalore \\ Bannerghatta Road, Bangalore - 560076 \\ \{gunupudi. laxmi10, rahul\} @iimb. ernet. in
}

\begin{abstract}
Agriculture is an important economic activity and is a primary driver of economic growth of many developing countries. Improving the performance and profitability of agricultural markets will lead to the growth of the agricultural sector. Information and Communication Technologies (ICT) based Agricultural Market Information Systems (AMIS) is a development initiative which promises to empower the stakeholders of the agricultural supply chain with information and aid the development of the agricultural sector. Many attempts have been made by governments in a number of developing countries to provide AMIS, with a poor success rate. It is important to understand the factors that determine the success or failure of these systems. In this paper we take the theoretical lens provided by Bartels' theory of market separations in order to define the success of AMIS. Using a technical/rational view, we conduct a two level analysis of market separations - those in agricultural markets and those in AMIS services markets. We find that information separation is a strong feature that exists in agricultural markets and AMIS provide good means of reducing this separation. Success of AMIS is defined by the reduction of market separations at both these levels. Later we go beyond technical rationality and note that socio-political issues limit the utilization of market information provided by AMIS. Thus we state that socio-political separation of agricultural markets must also be tackled in order to successfully implement AMIS. A comprehensive policy environment in a region can help reduce these separations.
\end{abstract}

Keywords: Market Separations, AMIS, ICT.

\section{Introduction}

Socio-economic and industrial development of any nation depends upon the growth in its agricultural sector. It is particularly true in the case of developing countries, where a large percentage of the population lives in rural areas and agriculture is their primary occupation (Ogen, 2007). This sector drives the growth of the economy by meeting food requirements and providing raw materials to industries and by generating employment and earning foreign exchange.

Agricultural produce is traded in agricultural markets. Agricultural marketing spans across numerous activities covering all the services involved in moving an 
agricultural produce from the farm to the consumer such as planning production, growing and harvesting, grading, packing, transport, storage, agro- and food processing, distribution, advertising and sale. In developing countries, traditional agricultural markets function poorly. Market information systems can provide a means to reduce the inefficiencies and power inequalities that exist in these markets(Shepherd, 1997; Gunupudi \& De, 2011). Proliferations of ICT-based AMIS can help in achieving economic efficiency, performance and equity in these markets. They empower various stakeholders in the agricultural supply chain with information about different markets. This can help in correcting large scale imperfections that exist in rural and unorganized markets, thereby making them more efficient and productive (Abraham \& Rueben, 2008). Information from these systems has been posited to benefit all the stakeholders of the sector. Farmers take better decisions with regards to choice of markets, arbitrage, and production planning. Traders benefit from lower costs of gathering information. Government and policy makers take informed decisions about food security planning and policy (Islam \& Gronlund, 2010).

Though many attempts have been made by a number of governments to provide Agricultural Market Information Services (AMIS), the success rate is poor. In this paper, we take both development and Information Systems (IS) perspectives to understand the factors that determine the success of AMIS. The focus of the development perspective is on improving the efficiency and performance of agricultural markets. The IS perspective deals with implementing an efficient and usable system that provides useful and reliable information to the stakeholders. Diversity has been an implicit and dominant theme in IS research and theories from several reference disciplines have contributed to theoretical foundations of IS discipline (Benbasat \& Weber, 1996). Given the context of markets, we borrow the theory of market separations from the marketing discipline to understand the functioning of agricultural markets. We take the developmental perspective to understand the separations in agricultural markets and the IS perspective to understand the separations in AMIS services markets. In the following section we take a look at the functioning of agricultural markets in developing countries.

\section{Agricultural Markets in Developing Countries}

Markets represent the meeting space for demand and supply of commodities. In economic terms it is any structure meant for exchange of goods, services and information between buyers and sellers. Market prices are a reflection of demand-supply equations, production costs and marketing costs.

Economies of many developing countries are heavily dependent on agricultural sector and allied activities (Ogen, 2007) (in India, for instance, agriculture and allied activities contribute about $30 \%$ of Gross Domestic Product). Agricultural produce is traded in agricultural markets. In developing countries, traditional agricultural markets function poorly and homogeneous goods sold at different locations do not have the same prices (net of transportation costs) (Shepherd, 1997). In 2007, World Bank has given top priority for improving market efficiency as a part of the agriculture-for-development agenda. They believe that the context of failed markets determines the livelihood of people in rural areas in developing countries and that secured and sustained agricultural growth is 
only possible when markets function properly (WorldBank, 2008). To understand the functioning of agricultural markets in developing countries, we look at the situation in India in the next section.

\subsection{Functioning of Agricultural Markets in India}

Agricultural marketing is primarily concerned with buying and selling of agricultural products. Let us consider the case of Indian agricultural markets. In the earlier days when the village economy was more or less self-sufficient, each neighbourhood had its own designated location where buyers and sellers engaged in trade, without the presence of a strong institution and the farmer sold his produce to the consumer on a cash or barter basis. Today's agricultural marketing has to undergo several exchanges before it reaches the consumer in the form of assembling, preparation for consumption and distribution. Sale of agricultural produce depends upon the demand for the product at that time, availability of storage etc. The products may be sold directly in the market or it may be stored locally for the time being. Moreover, it may be sold as it is gathered from the field or it may be cleaned, graded and processed by the farmer or the merchant of the village. Distribution system must ensure the balance between the supply with the existing demand by wholesaling and retailing in various points of different markets like primary, secondary or terminal (Biswas, 2011).

Farmers, small and large traders, Government and policy makers are the major stakeholders of these agricultural markets. Farmers sell their produce to traders in the markets. Small traders trade in few mandis and they buy products from farmers and sell them to the wholesaler. Large traders trade at a number of markets. They have their own information networks. These traders invest in storage and transportation facilities and take advantage of both spatial and temporal arbitrage. This prevents the entry of small traders to the markets. Government has an important role to monitor differences in prices at which famers and retailers sell their products in various markets to check for inefficiencies. Policy makers are responsible for making policies with regard to food security. They have to identify early warnings of food shortages and manage food security reserves (Helder \& Nyhoff, 1994). They also have to be alert to the traders' association's lobbying activities.

Indian Government has framed some salient policies for efficient functioning of agricultural markets (Thomas, 2003). "Primary commodities" were defined, for which the government sets a minimum support price (MSP). A farmer can sell his produce to the government if the market price falls much below the MSP. Formal agricultural commodities markets are restricted to localized wholesale markets called mandis where the price of these commodities is determined. In mandis traders purchase commodities from farmers and then auction and sell these commodities to wholesalers. If the prices of these commodities go below MSP, traders have to purchase the commodities at MSP and they are later compensated by the mandis for the price differential. Only those traders with a license from the mandi can buy and sell commodities at the mandi. Mandis collect a market fee from the traders. Commodity prices are determined by a process of auction which happens at a fixed time at each mandi. As each lot is auctioned, a new price is set. 


\subsection{Agricultural Market Information Systems (AMIS)}

Agricultural Market Information System (AMIS) is defined as "A service, usually operated by the public sector, which involves the collection on a regular basis of information on prices and in some cases, quantities of widely traded agricultural products from rural assembly markets, wholesale and retail markets, as appropriate, and dissemination of this information on a timely and regular basis through various media to farmers, traders, government officials, policy makers and others including customers."(Shepherd, 1997)

It is a system that links information from various agricultural markets across the country and provides the same to the various stakeholders. It involves the usage of ICT, such as the internet and mobile phones, in co-ordination with mass media like radio, newspaper and television along with blackboard displays and public addressing systems at the market place. The idea is to provide a reliable information network for data collection and information dissemination. Prior research has investigated the spread and use of AMIS in least developed countries in terms of users, management, funding, infrastructure and data (Islam \& Gronlund, 2010). Their findings show that data collection and information dissemination are two major activities involved in providing AMIS.

The systems provide current and up-to-date information on prices and market conditions such as transportation details and weather conditions based on raw data collected. They also gathers data over time and provide useful analysis regarding seasonal price trends, market trends, forecasts and comparative analysis of prices across markets.

These systems can be classified based on the ownership, technology used and coverage. Ownership of these systems varies from state-run market information systems to privately managed ones and also public-private ownership arrangements where the initiative is taken up by semi-government organizations or by partnership between government and private agencies. Technology used can be traditional like the newspapers, bulletin boards or price boards at the markets; semi-modern like television and radio; modern like internet and mobile phones. Coverage varies from being local which is restricted to a particular region or state to national where the information dissemination happens across the country.

AMIS provides numerous benefits to its stakeholders. Spatial arbitrage is the process of exchange of commodities taking advantage of price differences across markets which exceed the transaction costs (of operating in those markets) and temporal arbitrage is the process of exchange of commodities taking advantage of price differences over time. Current information is generally useful for spatial arbitrage and historic information is useful for temporal arbitrage. With the availability of information, farmers can take advantage of both spatial and temporal arbitrage. Analysis of this current and historic data helps in identifying trends which can further help farmers in taking decisions on production planning (Shepherd, 1997). Knowledge of prevailing market prices can help farmers negotiate with the traders from a position of relative strength. Depending on customer preferences and demand (reflected in price information), they may even improve the quality and presentation of their product. Analysis of market and price trends from AMIS can help them make informed decisions on the quality and quantity of their produce. They may change their marketing 
plans and may even take advantage of group marketing (Holtzman \& al., 1993). Large traders can reduce their investment on private information networks and make use of their storage capacities to benefit from temporal arbitrage. Many new small traders may enter the markets with the availability of market information (Shepherd, 1997). Government can make use of reliable market information to evaluate market performance and to identify macro economic constraints (Evans \& Lynton, 1997). Policy makers can get early warnings of food shortages and use forecast data for production planning and for managing food security reserves (Evans \& Lynton, 1997). Customers can also negotiate with traders better with the available information.

\section{Theory of Market Separations}

Bartels' theory of market separations (Bartels, 1968) describes four kinds of separations between the consumers and producers that impact exchange and consumption of agricultural products. Markets can function efficiently when these separations are reduced. The four kinds of separations are described as follows:

- Spatial - Consumers and producers are separated by physical distances.

- Temporal - Consumers and producers are separated by time difference between the production and consumption of goods.

- Informational - Consumers and producers are separated by knowledge of products and market conditions.

- $\quad$ Financial - Consumers and producers are separated by lack of purchasing power at the time of need.

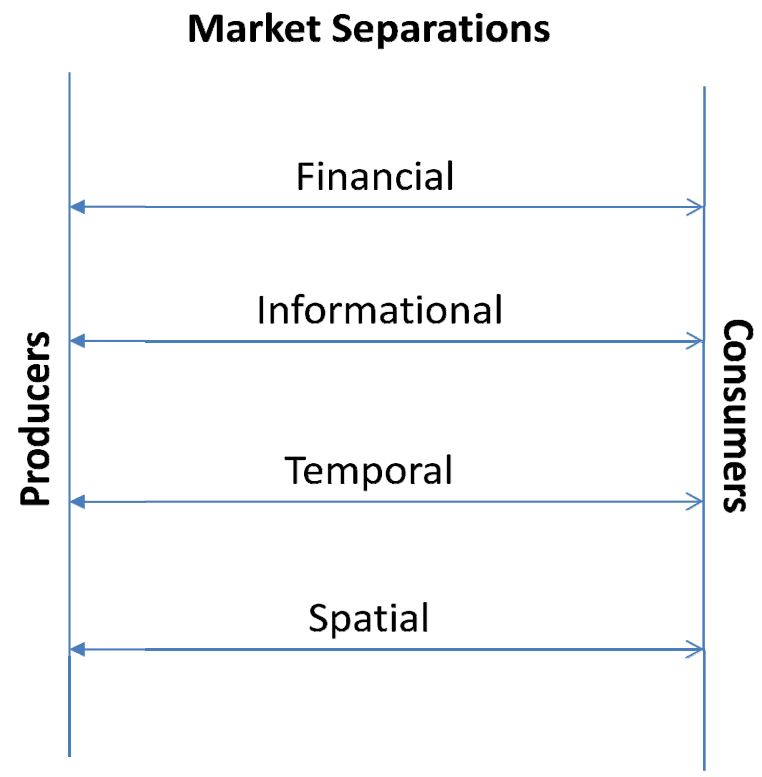

Fig. 1. Market Separations from Bartels' Theory 
These separations (as illustrated in Figure 1) prevent successful market transactions between the producers and consumers. The strength and impact of each of these separations depends upon the social context of the markets (Bartels, 1968). This theory has been used in IS research earlier to analyze the role of Information and Communication Technologies (ICTs) in development at the Bottom of the Pyramid (BOP) (Tarafdar \& Singh, 2011). In the next section we will briefly explain the research objective and methodology.

\section{$4 \quad$ Research Question and Methodology}

In this paper, we would like to take the market separations perspective to understand the functioning of agricultural markets in developing countries and the role of ICTs in bridging these separations. Given the context, this theory is appropriate in understanding the inefficiencies of agricultural markets. We would like to address the research question: How can AMIS systems be designed to close the separations in markets for agricultural commodities in developing countries?

We primarily rely on published literature on agricultural markets and design of AMIS. This is a conceptual paper based on prior research, where we provide a new theoretical lens for evaluating market information systems from both a developmental and IS perspective. We also look at some field studies to support our argument.

In the following sections we take up a detailed analysis of these markets and associated IS using the theoretical lens of market separations theory.

\section{Technical/Rational Analysis of Agricultural Markets and AMIS}

The body of knowledge based on technical rationality is rooted in the normative research paradigm concerned with systematic reasoning, decision making, and governing of practice through methods, techniques and technologies (Avgerou \& McGrath, 2007). Using technical rationality as our driver, in this section, we will take up the analysis of agricultural markets and AMIS at two levels. At the higher level we map the inefficiencies of agricultural markets in developing countries to the market separations that exist between producers and consumers based on Bartels' theory. Here the goods of exchange are the agricultural products. We will analyze the role of AMIS in reducing these separations.

At the second level we consider the services provided by AMIS as the goods of exchange and map the market separations that exist between the providers of these services and the consumers. We will look at the AMIS design process which can reduce these separations.

\subsection{AMIS as a Solution to the Market Separations in Agricultural Markets}

In this section we will identify and map the four separations in agricultural markets as identified by Bartels' theory. According to his theory, depending on the context of application, the strength and impact of each of these separations vary. 
In the context of agricultural markets, the producers are farmers who want to sell their agricultural products in the markets. They represent the supply side in the equation. Consumers are those people who are in need of and are willing to purchase the agricultural produce for consumption. They represent the demand side. Market prices of the products are reflective of the demand and supply.

The following is the analysis of agricultural markets on the basis of FAO's bulletin (Food and Agricultural Organization of the United Nations (Shepherd, 1997)) along the lines of market separations theory:

- Spatial: This separation occurs when producers are unaware of the demand for their produce in markets other than their regular trading market and consumers are unaware of the availability of the product of their choice in other markets. Market prices are indicative of demand and supply. Market price information from various markets and availability of transportation facilities can help reduce this separation. Farmers can transport their produce to the markets where there is demand and take advantage of spatial arbitrage.

- Temporal: This separation occurs when the producers are unaware of the demand and price trends for their produce. This happens under certain conditions when demand and supply are out of phase and demand lags supply. Availability of information on historical price and demand trends and their analysis to forecast demand can help farmers take decisions about storage of their produce to take advantage of temporal arbitrage and thereby reduce temporal market separation.

- Financial: This separation occurs when buyers do not have purchasing power at the time when they have willingness or need to buy. This happens when producers do not have the information on demand for their produce at the time of sale. Again, information on demand cycles for their produce and forecasts about the same can help farmers plan their production and reduce financial market separation.

- Informational: This separation occurs as a result of differential information held by producers and consumers on product prices and market conditions. This can be considered as an outcome of information asymmetries that exist in agricultural markets. Information asymmetry is defined "as a situation where some party in a transaction benefits from having preferential access to information” (Stiglitz, 2002). George Akerlof, Michael Spence and Joseph E. Stiglitz were awarded the Nobel Prize in the year 2001 in Economics for their study of markets with information asymmetry. Traders have preferential access to information in this context and they benefit from this advantage. They manipulate the information that both producers and consumers have in order to gain this advantage.

The following table summarizes the four market separations in agricultural markets and their possible solutions. 
Table 1. Market Separations in Agricultural Markets

\begin{tabular}{|c|c|c|}
\hline \multicolumn{3}{|c|}{ Market Separations in Agricultural Markets } \\
\hline Market Separation & Underlying Cause & Possible Solution \\
\hline Spatial & $\begin{array}{l}\text { Producers unaware of demand } \\
\text { and consumers unaware of supply } \\
\text { in different markets }\end{array}$ & $\begin{array}{c}\text { Provision of Market price } \\
\text { information and transportation } \\
\text { facilities. }\end{array}$ \\
\hline Temporal & $\begin{array}{c}\text { Demand and suppply out of phase } \\
\text { and demand lags supply }\end{array}$ & $\begin{array}{l}\text { Provision of information on } \\
\text { price trends and access to } \\
\text { storage facilities. }\end{array}$ \\
\hline Financial & $\begin{array}{l}\text { Demand supply mismacth } \\
\text { resulting from improper } \\
\text { production planning }\end{array}$ & $\begin{array}{l}\text { Provision of information on } \\
\text { demand and price trends for } \\
\text { production planning }\end{array}$ \\
\hline Informational & $\begin{array}{l}\text { Lack of information on market } \\
\text { prices and market conditions }\end{array}$ & $\begin{array}{l}\text { Provision of information on } \\
\text { market prices and market } \\
\text { conditions }\end{array}$ \\
\hline
\end{tabular}

From the analysis of the above separations, we can easily conclude that solving the problem of informational separation will also reduce the other separations in the context of agricultural markets. Availability of information on market conditions and prices across the region or state will help producers plan their production and take advantage of spatial and temporal arbitrage.

This can be illustrated as shown in Figure 2.

\section{Agricultural Market Separations}

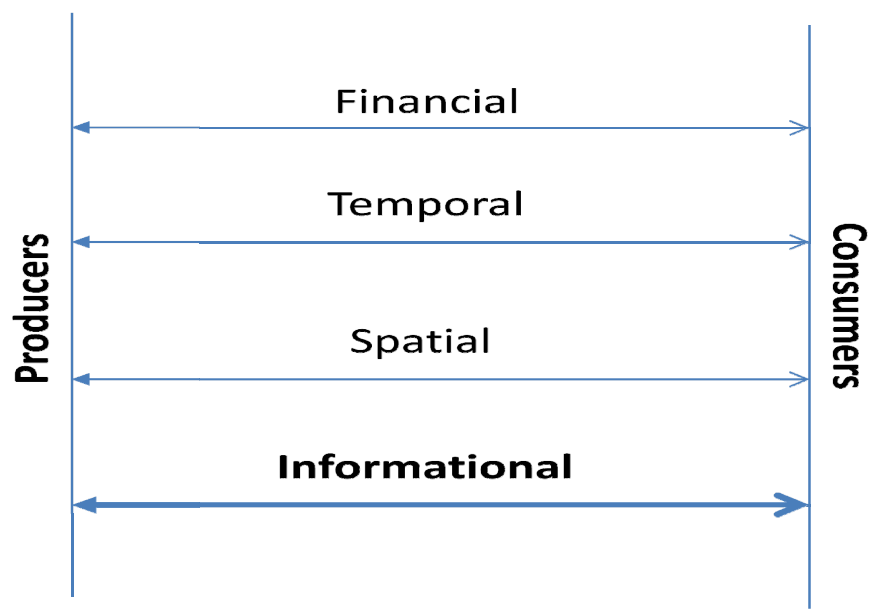

Fig. 2. Market Separations that exist in Agricultural Markets

AMIS provides both current information and analysis of historic data. Current information will help producers and consumers in reducing the spatial and informational separations. Demand and price trends and forecasts from the analysis of historic 
data will help producers plan their production or store their produce thereby reducing temporal and financial separations.

\subsection{Market Separations Perspective of AMIS Services and AMIS Design}

Considering the services provided by AMIS as the goods of exchange, in this section we map the market separations that exist between the providers of these services and the consumers.

In this case, providers of these services who are responsible for collection of raw data from markets and dissemination of information are the producers. They represent the supply side. Stakeholders of agricultural markets who are interested in the information being provided by these services are the consumers and they represent the demand side.

Prior work on AMIS (Gunupudi \& De, 2011) has come up with some guidelines for designing AMIS for economic sustainability and effectiveness. Their guidelines define the processes for data collection and information dissemination. Following is the analysis of AMIS service market separations and possible design solutions for reducing these separations based on the above guidelines.

- Spatial - This market separation occurs when consumers are not able to access information from AMIS. In order to reduce this separation, AMIS must aim to reach target audience through locally available and accessible modes of information dissemination. Full-time, trained, data collectors must ensure that up-to-date and reliable data is collected. The focus must not be on technological sophistication of medium of information dissemination, but on provision of accurate and consistent information to a wide target audience (Shepherd, 1997).

- Temporal - This market separation occurs when consumers do not have information on historical prices or demand trends and are unable to forecast prices and demand. This separation can be reduced by providing extension services where one can obtain information on demand and price trends, price forecasts, crop patterns and other related aspects. Information from these services must help target audience take important decisions. Mobile phone services have been identified in prior research as a good means of providing these extension services(Davis, 2008).

- Financial - This market separation occurs when consumers are not in a position to afford the services provided by AMIS. To reduce this separation, during the design phase, broadcasting charges and sponsors should be identified and economically sustainable modes of dissemination must be chosen. Basic information such as market prices and market conditions which constitute current information must be provided free to all the target audience and extension services which provide information on price trends and forecasts must be provided on a pay-per-use basis. This will ensure that the services provided are equitable and at the same time ensure the economic sustainability of the system, thus reducing financial market separations in this context (Dinar, 1996). 
- Informational - This market separation is a result of consumers' ignorance of available AMIS services and their access procedures. AMIS design must ensure that consumers are aware of all the available services on AMIS. Design must aim to increase the perceived value of these services. Offering training courses to farmers on the usage of these services (Singh, 2006) is a good way of reducing this markets separation. Field workers can also help people interpret the information received from these services.

These separations in AMIS services markets are summarized in the following table (Table 2).

Table 2. Market Separations in AMIS Markets

\begin{tabular}{|c|c|c|}
\hline \multicolumn{3}{|c|}{ Market Separations in AMIS Markets } \\
\hline Market Separation & Underlying Cause & Possible AMIS Design Solution \\
\hline Spatial & $\begin{array}{l}\text { Consumers unable to access } \\
\text { information from AMIS }\end{array}$ & $\begin{array}{c}\text { Locally available and accessible } \\
\text { medium of information } \\
\text { dissemination must be chosen. } \\
\text { Trained and full-time data collectors } \\
\text { must ensure up-to-date reliable } \\
\text { information. }\end{array}$ \\
\hline Temporal & $\begin{array}{c}\text { Consumers do not have } \\
\text { information on price and demand } \\
\text { trends and forecasts }\end{array}$ & $\begin{array}{l}\text { Extension services of the system can } \\
\text { provide specific information on price } \\
\text { and demand trends in markets. This } \\
\text { information can be disseminated } \\
\text { through mobile phones. }\end{array}$ \\
\hline Financial & $\begin{array}{c}\text { Consumers cannot afford AMIS } \\
\text { services }\end{array}$ & $\begin{array}{l}\text { Revenue model must be designed to } \\
\text { ensure both financially sustainability } \\
\text { and equitability of the system. }\end{array}$ \\
\hline Informational & $\begin{array}{c}\text { Consumers are not aware of AMIS } \\
\text { services and their access } \\
\text { procedures }\end{array}$ & $\begin{array}{l}\text { Marketing of these services must } \\
\text { also train the users on the usage of } \\
\text { the services and interpretation of } \\
\text { information received }\end{array}$ \\
\hline
\end{tabular}

From the analysis of above separations, we understand that following design guidelines for effective and reliable AMIS, providers can ensure that market separations are reduced and services are utilized by the stakeholders of agricultural markets. Choice of an appropriate information dissemination medium reduces spatial separations and provision of extension services reduces temporal separations. Suitable revenue model ensures that financial separation is reduced and marketing of services and training on usage of these services and interpretation of information received reduces informational separation.

In the following section we integrate the two levels of analysis to define successful implementation of AMIS in developing countries. 


\section{Beyond Technical Rationality: Fifth Dimension of Market Separations in Agricultural Markets (Socio-Political Separations)}

AMIS is one of the initiatives that stems from active innovation perspective of technology and development. According to this perspective, markets will not deliver to the poor and interventions in the form of innovations are imperative to meet development goals (Heeks, 2008).

As stated by Heek's (2008) it is important to evaluate the ICT for Development initiatives for success. In order to define success for an AMIS implementation, we need to take two perspectives. One is the developmental perspective and the other is the IS perspective.

The primary developmental objective behind providing AMIS is to make the agricultural markets in developing countries more efficient and profitable. This will lead to the growth of the agricultural sector, which is a primary driver of GDP for these countries, there by contributing to the development of the country as a whole. Simon defined human development "as the process of enhancing individual and collective quality of life in a manner that satisfies basic needs (as a minimum), is environmentally, socially and economically sustainable and is empowering in the sense that people concerned have a substantial degree of control over the process through access to the means of accumulating social power" (Simon, 1997). Therefore AMIS supported by ICTs can be defined as a development initiative that empowers the stakeholders in the agricultural value chain with information.

From an IS perspective, AMIS has to be a usable system providing reliable information which is useful to the stakeholders. Scalability and sustainability are some of the measures of success of ICT for Development initiatives (Heeks, 2008).

In this paper, taking the theoretical lens of Bartels' market separations, we have analyzed market separations of AMIS at two levels. The first level deals with the market separations in agricultural markets corresponding to the developmental perspective. We identified informational separation as a strong separation in agricultural markets which can be reduced by the provision of AMIS. In the second level, we analyzed the market separations of the AMIS services markets, which correspond to the IS perspective. From the above analysis we can successfully conclude that success of any AMIS can be determined by its ability to reduce market separations at both these levels.

The above analysis involves a technical/rational view of agricultural markets. Primary assumption underlying this analysis is that, information provided by AMIS services will definitely be utilized in reducing these market separations. In the case of developmental initiatives like this, it is important to understand the socio-political context of implementations (Avgerou \& McGrath, 2007).

When we look at the socio-political context of AMIS implementation, we come upon many situations that limit the effective utilization of information provided by AMIS services. In the case of rural India, many farmers have limited outlets for their produce. They are constrained by traditional trading relationships with middlemen. 
These relationships can be attributed to many reasons. An obvious rational explanation is their dependence on these middlemen for credit which binds them in these relationships. Other socio-political barriers to utilization of information by farmers and other stakeholders are local power politics. Prior research has identified the following factors that cause socio-political separations:

- Caste - Caste shapes the outcomes of ICT implementations because of its influence on both the social and political contours of village life (Nicholas, 1968). Prior research findings on the outcomes of implementation of kiosks in India state that caste manifests itself "in everyday practices of access to, mobility around, sharing of knowledge about, and use of the kiosks" (De', 2009) (in the case of Bhoomi Kiosks for land records). Caste can act as a barrier in this context of AMIS with regards to access to both technology and agricultural markets.

- Community Membership - Similar to caste, membership to various communities creates barriers to utilization of information from AMIS. Prior research suggests that members of certain communities do not usually cross the boundaries that are created as a result of social structures that have been dominant over years. These boundaries prevent the movement of agricultural produce to markets that are in other regions or domains. This phenomenon has been observed in a study in Kuppam town (in the state of Andhra Pradesh in India), where the access to dealers in a market was driven by community membership. Members of certain communities did not access these dealers as they were from groups outside the 'boundary' of their community.

- Community Leader - In many areas, community leaders take a decision on the agricultural markets to trade for the entire community. Members of the community have to abide by the decision taken by the leader. This prevents the members of the community from trading in other markets.

- Gender - Prior studies by FAO in 2011 have noted that women in agricultural sector in developing countries have lower education and are lesser likely to have access to technology extension services compared to men. Gender roles within a specific geographic and cultural context determine the access to these services (FAO, 2010-2011). Also in some regions, access to agricultural markets is based on gender. Hence we consider gender as one of the barriers that contributes to socio-political separations in agricultural markets.

The following table (Table 3) highlights the underlying causes that contribute to socio-political separations. 
Table 3. Socio-Political Separations

\begin{tabular}{|l|l|}
\hline \multicolumn{2}{|c|}{ Socio-Political Separations } \\
\hline Causes & \multicolumn{1}{|c|}{$\begin{array}{l}\text { Underlying Reasons } \\
\text { Caste influences the access to } \\
\text { agricultural markets. }\end{array}$} \\
\hline Community Membership & $\begin{array}{l}\text { Membership to a community plays a } \\
\text { crucial in deciding the target } \\
\text { agricultural markets for sale. }\end{array}$ \\
\hline Community Leader & $\begin{array}{l}\text { Community leaders determine and } \\
\text { decide the target markets for } \\
\text { agricultural produce }\end{array}$ \\
\hline Gender & $\begin{array}{l}\text { Women have lesser access to } \\
\text { technology compared to men. } \\
\text { Women's access to agricultural } \\
\text { markets is restricted in some areas. }\end{array}$ \\
\hline
\end{tabular}

Agricultural Market Separations

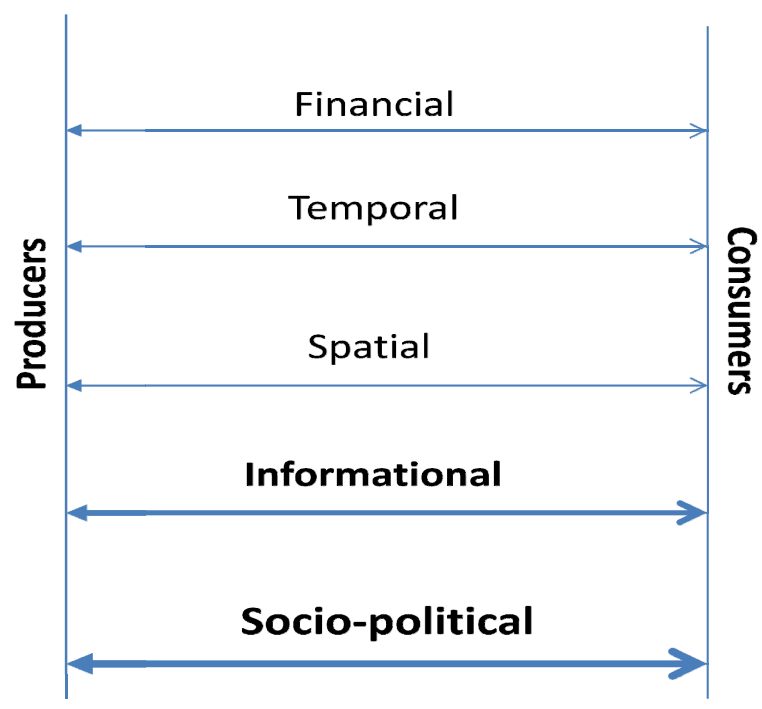

Fig. 3. Market Separations in Agricultural Markets - Beyond Technical Rationality

Taking this view, we find that, socio-political separations have a very strong impact in agricultural markets. In our view, this market separation is most difficult to tackle. Effective and efficient design of AMIS might reduce the market separations defined by Bartels' in this theory. But success of AMIS depends on reducing the socio-political separation that exists. It is important for policy makers to make appropriate 
policy changes to remove these socio-political barriers along with implementation of a system like AMIS. Thus wider policy environment in the country determines the success of AMIS to a large extent.

\section{Conclusion}

In this paper we make use of Bartels' theory of market separations to define success for the implementation of AMIS. The objective of the paper is to understand how AMIS systems can be designed to close the separations in markets for agricultural commodities in developing countries. From technical/rational analysis of separations in agricultural markets and markets for AMIS services, we find that informational separation is a strong factor in agricultural markets. Reduction in informational separation will eventually reduce other separations. AMIS empowers players in agricultural markets with the requisite information, thereby reducing the market separations. Effective design of AMIS can ensure reduction of separations in AMIS services markets. From a developmental perspective it is important to reduce separations in agricultural markets and from an IS perspective we need to reduce separations in AMIS service markets. Thus we define success of AMIS by the reduction of market separations at both these levels.

Going beyond the technical rationality, we find that market separations in the context agricultural markets are not limited to the four separations as defined by Bartels'. Socio-political context creates a number of barriers for the effective utilization of information provided and the impact of AMIS in reducing these separations is limited. Thus we identify the fifth dimension - socio-political separation in the context of these markets. Caste, community membership, community leaders and gender are some of the barriers that lead to this separation. Thus, it is extremely important to recognize diversity in contexts in order to achieve development outcomes from initiatives such as AMIS.

Implementation of AMIS must be accompanied by changes in wider policy environment to support the stakeholders in utilizing the information effectively. Policies related to credit, public-distribution, financial inclusion etc. will have an impact on the success of AMIS.

We believe that it is important to identify an appropriate theoretical lens to evaluate the success of IS in developmental contexts. Imperfections and separations in agricultural markets have been implicitly studied in prior research. This is a conceptual paper based on prior research on agricultural markets and AMIS, where we provide a new theoretical lens for evaluating market information systems from both a developmental and IS perspective. We also extend this theory to make sense of the socio-political factors that greatly impact such implementations. It demonstrates the suitability of this theory in determining the success of ICTs used in developmental contexts. We intend to empirically validate the concept put forward in this paper. 


\section{References}

Abraham, Rueben: Mobile Phones and Economic Development:Evidence from the fishing industry in India, vol. 4(1), pp. 5-17. The MIT Press (2008)

Avgerou, C., McGrath, K.: Power, rationality, and the art of living through socio-technical change. MIS Quarterly 31(2), 293-315 (2007)

Bartels, R.: The General Theory of Marketing. Journal of Marketing 32(1), 29-33 (1968)

Benbasat, I., Weber, R.: Research Commentary: Rethinking "Diversity" in Information Systems Research. Information Systems Research 7(4), 389-399 (1996)

Biswas, A.: Agricultural Marketing in India (July 4, 2011), http: / / www. domain-b.com/economy/agriculture/ 20040713_marketing.html (retrieved from TNAU Agritech PPortal)

Davis, K.E.: Extension in Sub-Saharan Africa: Overview and Assessment of Past and Current Models, and Future Prospects. Journal of International Agricultural and Extension Education 15(3), 15-28 (2008)

De', R.: Caste Structures and E-Governance in a Developing Country. In: Wimmer, M.A., Scholl, H.J., Janssen, M., Traunmüller, R. (eds.) EGOV 2009. LNCS, vol. 5693, pp. 40-53. Springer, Heidelberg (2009)

Dinar, A.: Extension Commercialization: How much to charge for extension services. American Journal of Agricultural Economics 78(1), 1-12 (1996)

Evans, Lynton, J.: Strategic Grain Reserves - Guidelines for their establishment Management and Operation. FAO Agricultural Services Bulletin 126

FAO. The State of Food and Agriculture (2010-2011), http: / / www. fao.org/docrep/013/i2050e/i2050e.pdf (retrieved from FAO)

Gunupudi, L., De, R.: Role of AMIS in Resolving Information Asymmetries in Agricultural Markets: Guidelines for AMIS Design. CPR South 6. Bangkok: Available at SSRN 1976188 (2011)

Heeks, R.: ICT4D 2.0: The next phase of applying ICT for international development. Computer 41(6), 26-33 (2008)

Helder, J., Nyhoff, J.-J.: Market Information for Early Warning. In: Document Presented to the SADC Early Warning System for Food Security Training Workshop, Harare (1994)

Holtzman, J., et al.: Market Information Systems and Services: Lessons from the AMIS Project Experience. Abt Associates, Bethesta (1993)

Islam, M.S., Grönlund, Å.: Agriculture market information services (AMIS) in the least developed countries (LDCs): Nature, scopes, and challenges. In: Wimmer, M.A., Chappelet, J.-L., Janssen, M., Scholl, H.J. (eds.) EGOV 2010. LNCS, vol.6228, pp. 109-120. Springer, Heidelberg (2010)

Nicholas, R.W.: Structures of politics in the villages of Southern Asia. In: Singer, M., Cohn, B.S. (eds.) Structure and Change in Indian Society pp. 234-284. Aldine Transaction (1968)

Ogen, O.: The Agricultural Sector and Nigeria's Development: Comparitive Perspective from the Brazilian Agro-Industrial Economy. Nebula 4.1, 184-194 (2007)

Shepherd, A.W.: Market information Services: Theory and Practice. Agricultural Services Bulletin No.125 FAO - The UN (1997)

Simon, D.: Development Reconsidered: New Directions in Development Thinking. Geografiska Annaler 79B(4), 183-201 (1997)

Singh, S.: Selected Success Stories on Agricultural Information Systems. Asia-Pacific Association of Agricultural Research Institutions (2006)

Stiglitz, J.E.: Information and the change in the Paradigm in Economics. The American Economic Review 92(3), 460-529 (2002) 
Tarafdar, M., Singh, R.: A Market Separations Perspective to Analyze the Role of ICT in Development at the Bottom of the Pyramid. In: Proceedings of SIG GlobDev Fourth Annual Workshop, Shanghai, China, December 03 (2011)

Thomas, S.: Agricultural commodity markets in India: Policy Issues for Growth. Indira Gandhi Institute for development Research, Goregaon (2003)

WorldBank, World Development Report, Retrieved from The International Bank for Reconstruction and Developmet/ The World Bank, The Washington DC, USA (2008), http: / / siteresources.worldbank.org/INTWDR2008/Resources / WDR_00_book.pdf 